\title{
Age-dependent glutamate induction of synaptic plasticity in cultured hippocampal neurons
}

\author{
Stav Sapoznik, Miriam Ivenshitz, ${ }^{1}$ and Menahem Segal \\ Department of Neurobiology, the Weizmann Institute of Science, Rehovot 76100, Israel
}

\begin{abstract}
A common denominator for the induction of morphological and functional plasticity in cultured hippocampal neurons involves the activation of excitatory synapses. We now demonstrate massive morphological plasticity in mature cultured hippocampal neurons caused by a brief exposure to glutamate. This plasticity involves a slow, $70 \%-80 \%$ increase in spine cross-section area associated with a significant reduction in the width of dendrites. These changes are age dependent and expressed only in cells $>18 \mathrm{~d}$ in vitro (DIV). Activation of both NMDARs and AMPARs as well as a sustained rise of internal calcium levels are necessary for induction of this plasticity. On the other hand, blockade of network activity or mGluRs does not abolish the observed morphological plasticity. Electrophysiologically, a brief exposure to glutamate induces an increase in the magnitude of EPSCs evoked between pairs of neurons, as well as in mEPSC frequency and amplitude, in mature but not young cultures. These results demonstrate an age-dependent, rapid and robust morphological and functional change in cultured central neurons that may contribute to their ability to express long term synaptic plasticity.
\end{abstract}

Diverse morphological and electrophysiological changes have been reported to follow enhanced excitatory synaptic activity in central neurons. It has been shown in in vitro preparations that increased neuronal activity produces new spines (Parnavelas et al. 1973; Engert and Bonhoeffer 1999; Goldin et al. 2001), which are likely to be innervated (Goldin et al. 2001). Electrical stimulation has been shown to induce growth of post synaptic filopodia-like protrusions, as well as of bifurcated spines in the hippocampus (Trommald et al. 1996; Maletic-Savatic et al. 1999; Nikonenko et al. 2003). Chemically induced long-term potentiation (LTP) causes an increase in spine volume (Otmakhov et al. 2004), but the time course of this change is not consistent across different studies as other groups have reported this to be a transient phenomenon (Lang et al. 2004; Matsuzaki et al. 2004). Following a brief glutamate application, Wang et al. (2005) found a rapid, long-lasting increase in the frequency of spontaneous miniature excitatory post-synaptic currents (mEPSCs). Metabotropic glutamate receptor activation (mGluR) caused a rapid long-term depression (LTD) of synaptic responses without a reported change in spine morphology (Carroll et al. 1999; Xiao et al. 2001), whereas others have been able to detect spine shrinkage associated with LTD (Zhou et al. 2004). A rapid elimination of spines following exposure to glutamate has been reported in cultured neurons as well (Halpain et al. 1998). Topical uncaging of glutamate, when paired with post-synaptic depolarization, has been reported to cause an increase in subsequent responses to glutamate, but this functional change is (Matsuzaki et al. 2004) or is not (Bagal et al. 2005) associated with a morphological change of the spine. Thus, exposure of neurons to glutamate can produce different and possibly contradicting postsynaptic changes that are not clearly associated with a functional synaptic change. The reason for this heterogeneity in reactivity to glutamate is not entirely clear, but it may have to do with the receptor type activated, the pattern of activation, the specific type, or the age of neurons studied.

\footnotetext{
'Corresponding author.

E-mail miriam.brodt@weizmann.ac.il; fax 972-8-9344140.

Article published online before print. Article and publication date are at http:// www.learnmem.org/cgi/doi/10.1101//m.351706.
}

We have now found that a brief exposure of cultured hippocampal neurons to glutamate induces striking and long-lasting changes in the morphology of dendritic spines as well as in their synaptic activity. These changes are age-dependent, associated with a sustained rise of $\left[\mathrm{Ca}^{2+}\right] \mathrm{i}$ and may represent a novel mode of morphological and functional plasticity.

\section{Results}

Glutamate induces changes in spine and dendrite dimensions

Striking morphological changes were observed in spine and dendrite dimensions $45 \mathrm{~min}$ following a transient, 1-min exposure of a 3-wk-old culture to $200 \mu \mathrm{M}$ glutamate. These changes include an increase of $74.4 \% \pm 8.83$ in spine cross-section area (six coverslips, 13 cells, 167 randomly selected spines), and a reduction of $17.8 \% \pm 3.19$ in dendrite width (three coverslips, 10 cells, 30 segments) (Fig. 1A,B,E). Following glutamate application, $65.3 \%$ of the cells reached a criterion of $20 \%$ change (see Materials and Methods). In control experiments, where no glutamate was added to the recording medium, the increase in spine area was $3.7 \% \pm 4.12$ (three coverslips, 10 cells, 100 spines), whereas the reduction in dendrite cross-section area amounted to only $3.0 \% \pm 2.96$ (three coverslips, nine cells, 27 segments). These effects were strikingly different from those of toxic levels of glutamate $(0.5-1 \mathrm{mM})$, which produced rapid blobbing of the dendrites and disappearance of spines, followed by neuronal swelling and death (Fig. 1C,D). Such changes were not found in the neurons studied herein.

The time course of changes in spine morphology was examined in the same set of spines 5, 15, 30, and $45 \mathrm{~min}$ after the transient exposure to glutamate. The increase in spine crosssection area was gradual, with an average increase of $14.8 \% \pm 8.73,39.4 \% \pm 8.73,54.1 \% \pm 10.71$, and $70.6 \% \pm 3.6$, respectively (three coverslips, seven cells, 109 spines) (Fig. 2A,B). The change in spine size was inversely correlated with its initial size. Small spines underwent a larger proportional change in size compared with big spines, although the absolute change was about the same in both groups. Spines ranging from $0.23-0.5$ $\mu \mathrm{m}^{2}$ expressed an increase of $135.82 \% \pm 10.9$ in spine size fol- 

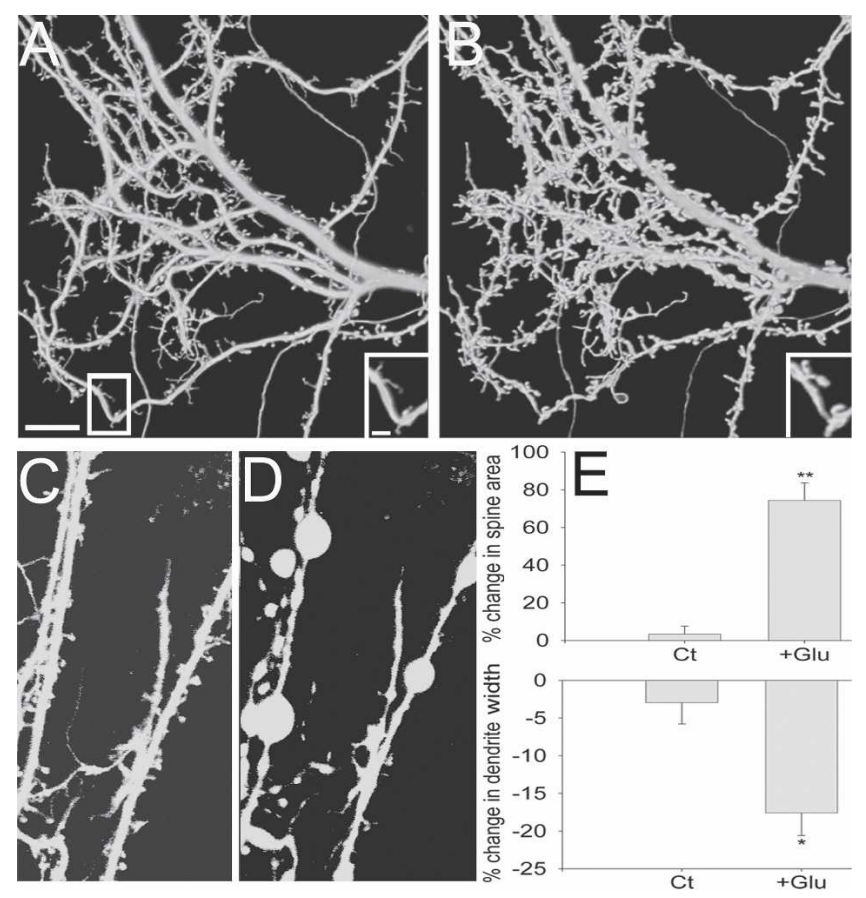

Figure 1. Spines swell and dendrites shrink following 1-min exposure to glutamate. Three-dimensional reconstructed images of spines and dendrites taken before $(A)$ and $45 \mathrm{~min}$ after $(B)$ glutamate application. Scale bar, $10 \mu \mathrm{m}$. (Insets) Higher power image of the cell before and after exposure to glutamate. Scale bar, $2 \mu \mathrm{m}$. $(C, D)$ Same as in $A$ and $B$, but before and after exposure to $500 \mu \mathrm{M}$ glutamate, showing spine blobbing and neuronal death. ( $E$, top) The average increase in spine cross-section area following exposure to glutamate ( $74.4 \%$; six coverslips, 13 cells, 167 spines) is significantly higher than control (3.7\%; three coverslips, 10 cells, 100 spines). (Bottom) The average reduction in dendrite width following exposure to glutamate $(17.8 \%$; three coverslips, 10 cells, 30 segments) is significantly higher than control $(2.96 \%$; three coverslips, nine cells, 27 segments). Ct indicates control; Glu, glutamate. ${ }^{* \star} p<0.01$, $* P<0.05$.

lowing glutamate application (24 spines). Larger spines, ranging from $0.5-1 \mu \mathrm{m}^{2}$, showed an increase of $84.2 \% \pm 5.23$ (66 spines). Spines with an initial area $>1 \mu \mathrm{m}^{2}$ showed an increase of only $43.28 \% \pm 2.05$ in spine size (76 spines) (Fig. 2C).

In addition to the effects on the shape of existing spines, glutamate induced spinogenesis, with $3.66 \pm 0.55$ new spines per $50-\mu \mathrm{m}$ dendritic segments in the treated cells, compared with only $0.98 \pm 0.4$ new spines in the control cells (three coverslips, 20 cells, 20 dendritic segments; $P<0.05$ ) (data not shown).

\section{Glutamate induction of morphological plasticity is age dependent}

Assuming that the effect of glutamate is better expressed in mature neurons, which are endowed with spines, analysis of morphological plasticity following glutamate application was conducted in cultures of different ages. Cells in cultures that were $<19 \mathrm{~d}$ in vitro (DIV), failed to express morphological plasticity. Plastic cells were observed only in mature cultures (19-25 DIV), and exhibited an increase of $74.4 \% \pm 8.83$ in the spine area following glutamate application (six coverslips, 13 cells, 167 randomly selected spines). The percentage of plastic cells in 19,20,21,24, and 25 DIV cultures was $40 \%$ (total of 20 cells examined), $63.0 \%$ (total of 27 cells), $73.3 \%$ (out of 15 cells), $81.8 \%$ (out of 11 cells), and $69.2 \%$ (out of 13 cells), respectively (Fig. 3C).

\section{Glutamate induces LTP in mature cells and LTD in young cells}

We recorded from pairs of neurons in culture and examined the presence of post-synaptic currents (PSCs) evoked in one cell of a pair, in response to an action potential discharge evoked by depolarizing the other one. The post-synaptic neuron was clamped at three different voltages $(-90,-60$, and $-30 \mathrm{mV})$ to determine the reversal potential and hence the nature of the PSC as being excitatory or inhibitory. Only excitatory (E) PSCs were analyzed in the present study. Baseline EPSCs were recorded for 5 min, at which time $200 \mu \mathrm{M}$ glutamate was added to the perfusate for $1 \mathrm{~min}$. Glutamate depolarized the recorded neurons to near 0 $\mathrm{mV}$, as expected. After a complete washout of the glutamate with standard recording medium, and once the membrane of the recorded neurons stabilized back at resting potential, EPSCs were evoked again. In young cells (11-18 DIV), a pronounced LTD of evoked EPSC amplitudes was recorded. This could be found for $>20$ min after washout of glutamate. In mature neurons, however (19-25 DIV), exposure to glutamate caused a significant LTP expressed as an increase in amplitudes of evoked EPSCs compared with baseline values (Fig. 4A).

To indicate the location of the long-term synaptic change, we studied the effect of a brief exposure to glutamate on miniature synaptic currents in mature hippocampal cultures. mEPSCs were recorded from separate populations of neurons before and after glutamate application. While resting properties of the cells were not affected by the brief exposure to glutamate, and membrane potential returned to rest levels (data not shown), mEPSC amplitude increased from $13.7 \pm 0.65 \mathrm{pA}$ to $18.4 \pm 1.93 \mathrm{pA}$ $(P<0.05)$ after glutamate. The frequency of mEPSC was also sig-

\section{A \\ B}
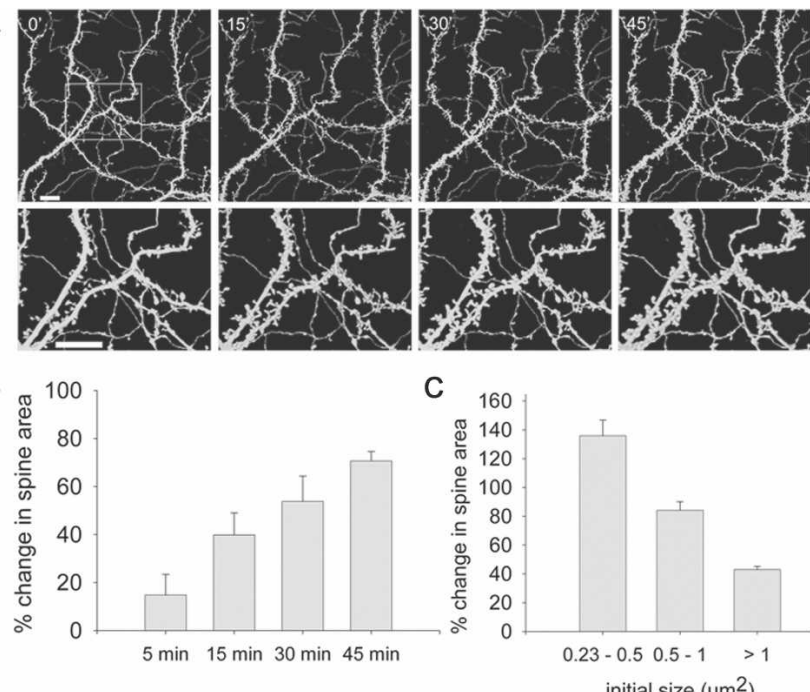

Figure 2. The increase in spine area is gradual and influenced by the initial spine size. $(A$, top) Three-dimensional reconstructed images of spines and dendrites taken at $0,15,30$, and 45 min following 1-min exposure to glutamate. (Bottom) Zoomed areas marked in top left image. Scale bars, $10 \mu \mathrm{m}$. (B) Averaged increase in spine area 5, 15, 30, and 45 min following exposure to glutamate $(14.8 \%, 39.4 \%, 54.1 \%$, $70.57 \%$; three coverslips, seven cells, 109 spines). One-way ANOVA for repeated-measures gave marginal results $\left(F_{(1,2)}=7.718, P<0.093\right)$. However, $t$-test comparing the initial and final time points yielded significant difference $(P<0.01)$. (C) The averaged increase in spine area is inversely correlated with its initial size (six coverslips, 13 cells; $0.23-0.5 \mu \mathrm{m}^{2}$ : $135.82 \%, 0.5-1 \mu \mathrm{m}^{2}: 84.2 \%,>1 \mu \mathrm{m}^{2}$ : 43.28\%). A significant correlation was found between the average increase in spine area and its initial size $\left(R_{\mathrm{s}}=-0.931, P<0.0001\right)$. In addition, the results were analyzed by linear regression: $\left(F_{(1,16)}=88.752, P<0.0001\right.$; $\left.\mathrm{R}^{2}=0.847\right)$ 
A

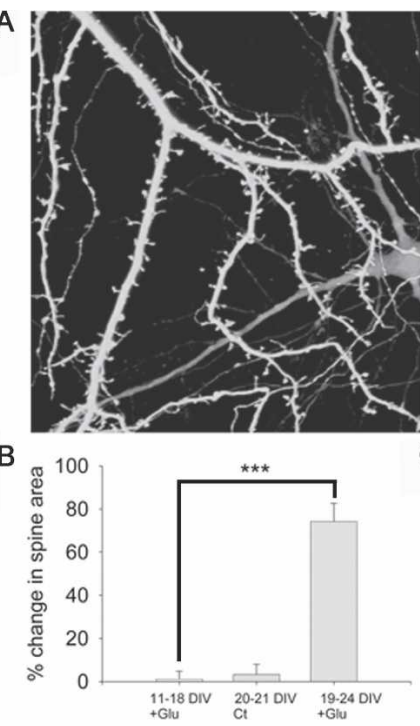

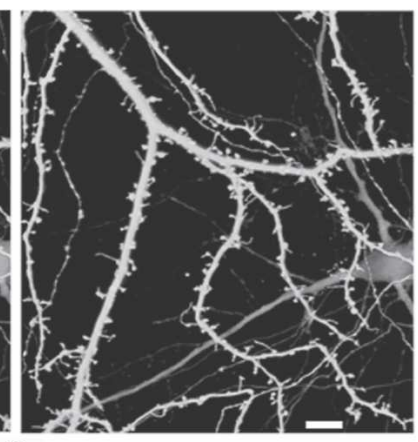

C

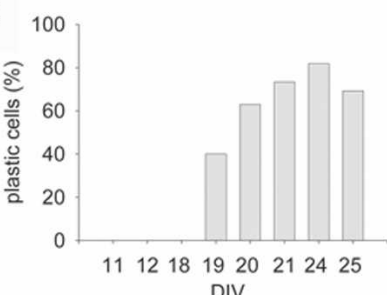

Figure 3. Glutamate does not cause morphological plasticity in young cells. $(A)$ Three-dimensional reconstructed images of spines and dendrites in 11 DIV cells before (left) and 45 min after a 1-min exposure to glutamate (right). Scale bar, $10 \mu \mathrm{m}$. (B) The average increase in spine area in young cells exposed to glutamate (1.01\%; five coverslips, 18 cells, 178 spines) is similar to control mature cells (3.66\%; three coverslips, 10 cells, 100 spines) and significantly lower than the change in mature cells exposed to glutamate ( $74.42 \%$; six coverslips, 13 cells, 167 spines). ${ }^{* * *} P<0.001$. (C) The percentage of plastic cells is age dependent $(0 \%$, $0 \%, 0 \%, 40 \%, 63 \%, 73.3 \%, 81.8 \%, 69.2 \%$ in $11,12,18,19,20,21,24$, and 25 DIV cells, respectively). $\chi_{(7)}^{2}=30.15, P<0.0001$.

nificantly increased from $29.3 \pm 8.16$ to $117.2 \pm 29.23$ events per minute after glutamate $(P<0.05)$ (Fig. 4B), as seen elsewhere (Malgaroli and Tsien 1992).

\section{Glutamate-induced plasticity is independent of persistent network activation}

To examine whether glutamate-evoked morphological plasticity requires persistently enhanced network activity (as was the case elsewhere) (Goldin et al. 2001), $0.5 \mu \mathrm{M}$ Tetrodotoxin (TTX) was added to the recording medium in experiments conducted on mature cultures. Changes in spine area reached $67.4 \% \pm 11.29$ above baseline (two coverslips, seven cells, 100 spines), similar to results of experiments with glutamate in normal medium $(P>0.05)$ (Fig. 5A,C). The dendritic width was reduced by $16.8 \% \pm 2.67$ (two coverslips, five cells, 25 segments), similar to control glutamate experiments $(P>0.05$, Fig. 5D). Under TTX and glutamate treatment, $75 \%$ of the cells reached the $20 \%$ criterion (Fig. 5E).

To ensure that the spine swelling and dendritic shrinkage are not a mere result of TTX application alone, several experiments were conducted in the presence of TTX, without the addition of glutamate. No spine swelling or dendritic shrinkage were observed in these cases (average spine increase of 7.8\% [one coverslip, three cells, 35 spines] and dendritic shrinkage of 3.3\% [1 coverslip, three cells, 17 segments] were observed, similar to control experiments) (Fig. 5B,C,D). These experiments indicate that the response to glutamate is not dependent on activation of the network but is caused by a direct effect on glutamate receptors.

Synaptic NMDARs and AMPARs, but not mGluRs, are necessary for glutamate-induced plasticity

The role of $N$-methyl-D-aspartate receptors (NMDARs), $\alpha$-amino3-hydroxy-5-methylisoxazole-4-propionate receptors (AMPARs), and mGluRs in glutamate-induced plasticity was studied by using

selective receptor antagonists. The involvement of synaptic NMDARs was studied by pre-exposing the mature hippocampal culture for $5 \mathrm{~min}$ to a $\mathrm{Mg}^{2+}$-free medium containing $200 \mu \mathrm{M}$ glycine and $10 \mu \mathrm{M}$ MK-801. This drug combination activates synaptic NMDARs, while MK-801 blocked the NMDA receptors in an open channel, noncompetitive manner. The drug is expected to stay at the synaptic site where it was originally bound, even after its washout from the tissue, leaving the nonsynaptic NMDA receptors still available for later activation by glutamate. This pretreatment blocked the effects of subsequent exposure to glutamate: Changes in spine and dendrite cross-section areas were now found not to differ from control values and reached only $11.3 \% \pm 2.18$ change (two coverslips, five cells, 100 spines) and $-7.75 \% \pm 0.32$ change (two coverslips, five cells, 25 segments) in spine area and dendritic width, respectively (Fig. 6A,D,E). These experiments indicate that glutamate activation of synaptic NMDARs is necessary for the production of the morphological plasticity.

AMPARs were blocked in mature cultures by exposing them to $20 \mu \mathrm{M}$ 6,7-dinitroquinoxaline-2,3-dione (DNQX). The in-
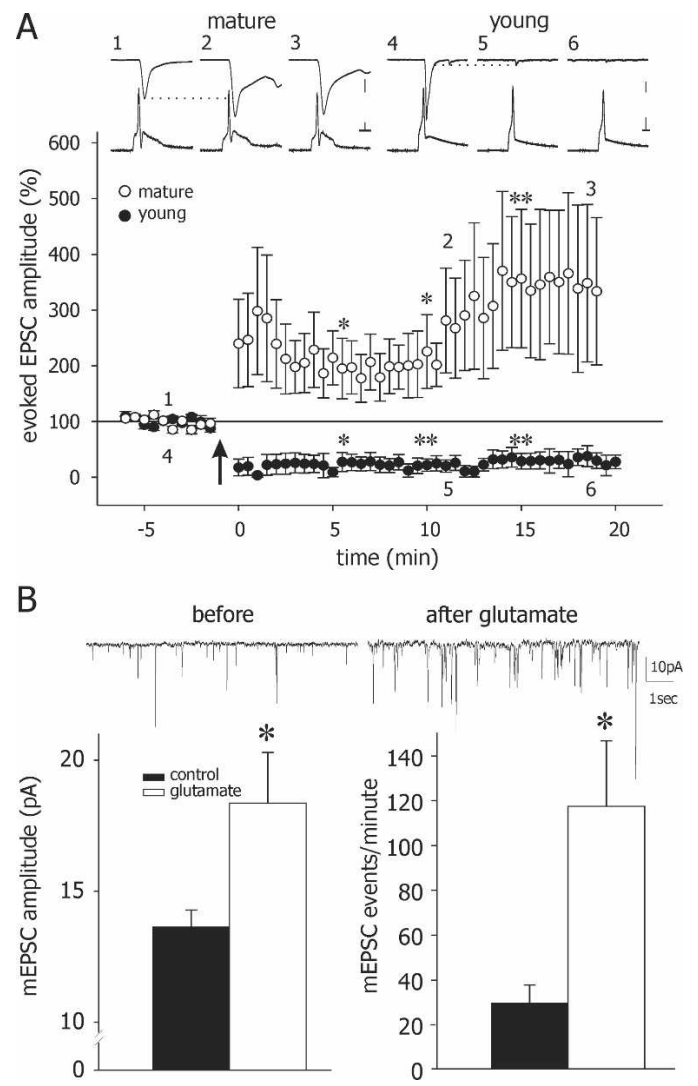

Figure 4. Glutamate induces potentiation of evoked and spontaneous synaptic currents in mature cells. $(A, t o p)$ Sample recordings of evoked action potentials in current clamp (bottom traces) and evoked postsynaptic EPSCs in voltage clamp mode (top traces) recorded in pairs of mature (left) and young (right) neurons before and after glutamate application. Numerals (1-6) indicate the point in time where these samples were taken. (Bottom) Averaged responses from mature and young cultures. Exposure to glutamate caused LTP in mature cells, averaging over twofold increase in mean EPSCs, and LTD in young cells, reaching $<50 \%$ of control values. Scale bars, $50 \mathrm{pA}, 20 \mathrm{mV}$, and $10 \mathrm{msec}$ in mature cells; $100 \mathrm{pA}, 20 \mathrm{mV}$, and $10 \mathrm{msec}$ in young cells. (LTP: $t$-test, ${ }^{*} P<0.05$, ${ }^{*} 0.05$, and ${ }^{* *} 0.005$ for 5,10 , and $15 \mathrm{~min}$, respectively, following glutamate application. LTD: $t$-test, $P<0.05,0.005$, and 0.005 for 5,10 , and 15 min, respectively, following glutamate application). (B) In mature cells, glutamate induced an increase in mEPSC amplitude (from 13.73 pA before to $18.45 \mathrm{pA}$ after glutamate; $n=11$ and 14 , respectively) and frequency (from 29.27 events/min to 117.18 events $/ \mathrm{min}$ ). $t$-test, ${ }^{*} P<0.05$. 
A

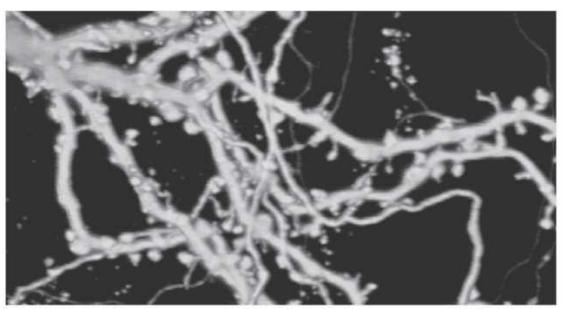

B

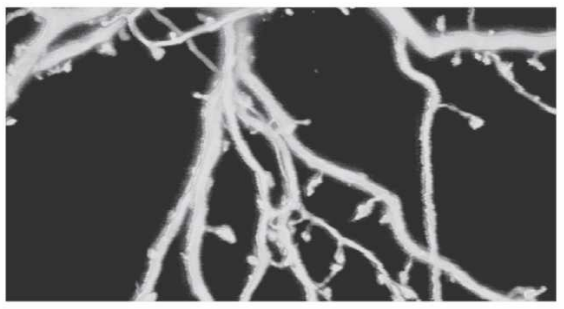

C

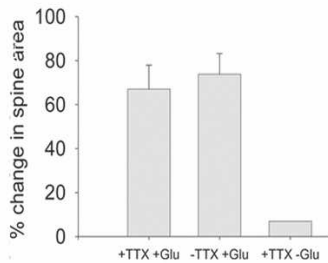

D

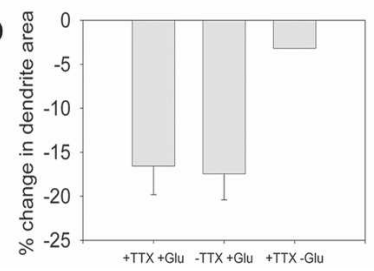

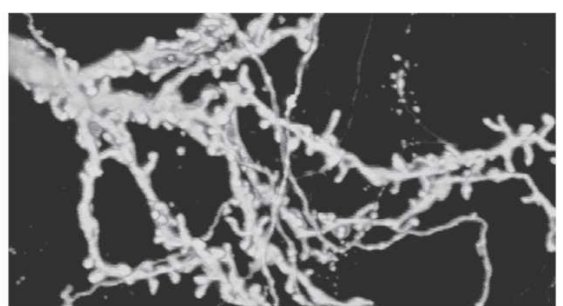

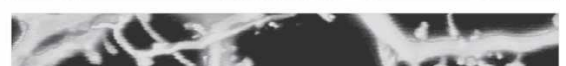

Figure 5. Sustained network activity is not required for glutamate-induced plasticity. ( $A$ ) Threedimensional reconstructed images of spines and dendrites in the presence of $0.5 \mu \mathrm{M} T \mathrm{TX}$, before (left) and $45 \mathrm{~min}$ after (right) glutamate application. (B) Three-dimensional reconstructed images of spines and dendrites in the presence of $0.5 \mu \mathrm{M}$ TTX alone before (left) and 45 min later (right). Scale bar, 10 $\mu \mathrm{m}$. (C) The average increase in spine area following glutamate application in the presence of TTX is similar to control (67.36\%; two coverslips, seven cells, 100 spines and $74.42 \%$; six coverslips, 13 cells, 167 spines, respectively), but higher than the change in cells which were exposed only to TTX and not to glutamate (7.82\%; one coverslip, three cells, 35 spines). (D) The average reduction in dendrite area following glutamate application in the presence of TTX is similar to control (16.78\%; two coverslips, five cells, 25 segments and $17.8 \%$; three coverslips, 10 cells, 30 segments respectively), but higher than the change in cells which were exposed only to TTX and not to glutamate (3.34\%; one coverslip, three cells, 17 segments). (E) The percentage of plastic cells in the presence of TTX is similar to glutamate. $\chi_{(1)}^{2}=0.09$.

crease in spine area in the presence of DNQX was only $9.6 \% \pm 6.07$ above baseline (two coverslips, eight cells, 100 spines). The reduction in dendrite width was $4.2 \% \pm 0.06$ (two coverslips, five cells, 25 segments). These values are not significantly different from controls (Fig. 6B,D,E).

The involvement of mGluRs was examined by exposing the cultures to $250 \mu \mathrm{M}$ MCPG. In the presence of the antagonist, spine area increased by $58.6 \% \pm 9.35$ above control (three coverslips, nine cells 100 , spines), whereas the reduction in dendrite area was $17.4 \% \pm 0.97$ (three coverslips, 10 cells, 30 segments), similar to normal glutamate experiments (Fig. 6C,D,E). Following MCPG application, $68.8 \%$ of the cells reached the $20 \%$ criterion (Fig. 6F). Thus, mGluRs do not seem to be involved in the glutamate-evoked morphological plasticity.

\section{Presence of $\mathrm{Mg}^{2+}$ does not affect glutamate-induced plasticity}

NMDARs are blocked at resting potential by $\mathrm{Mg}^{2+}$ ions. Depolarization through the AMPARs enables release of the $\mathrm{Mg}^{2+}$ block and facilitates opening of the channel. Thus, blockade of AMPARs can influence neuronal plasticity not only by inactivation of the receptor itself but also via its influence on NMDAR activity. To test this second possibility, blockade of AMPARs by DNQX was carried out using $\mathrm{Mg}^{2+}$-free medium, in order to facilitate NMDAR activation. Analysis of changes in spine and dendrite area showed that DNQX blocked morphological plasticity even in the absence of $\mathrm{Mg}^{2+}$. A $4.7 \% \pm 4.99$ increase in spine area was

E

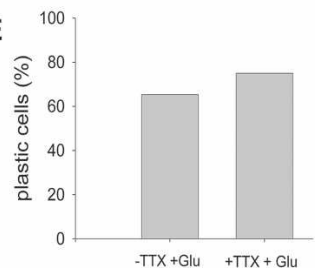

measured following application of DNQX and glutamate in $\mathrm{Mg}^{2+}$-free medium (two coverslips, five cells, 50 spines). The reduction in area of the dendrites was $3.1 \% \pm 4.06$ (two coverslips, six cells, 28 segments). As a control, changes in spine and dendrite areas were measured in $\mathrm{Mg}^{2+}$-free solution. In this case, morphological plasticity was not abolished. The average increase in spine area was found to be $68.9 \% \pm 4.97$ (two coverslips, four cells, 50 spines), whereas the average reduction in dendrite width was $21.2 \% \pm 4.16$ (two coverslips, five cells, 25 segments, all data not shown). Under this treatment, $52.6 \%$ of the cells reached the $20 \%$ criterion. These results indicate that the presence of $\mathrm{Mg}^{2+}$ did not affect glutamate-induced plasticity.

\section{Blockade of protein kinase $\mathrm{C}$ affects} glutamate-induced plasticity

Several protein kinases have been shown to play a crucial role in morphological plasticity and LTP induction and maintenance. The involvement of PKC in glutamate-induced plasticity was examined in mature cultures, using $1 \mu \mathrm{M}$ GF109203X. It affected the change in spine area but not the change in dendrite width. In the presence of the drug, spine area increased to only $41.09 \% \pm 1.43$ (two coverslips, four cells, 70 spines) above baseline. Dendrite width was reduced by $18.0 \% \pm 2.13$ (two coverslips, three cells, 15 segments) (Fig. 7A,B). Following GF109203X application, only $31.5 \%$ of the cells reached the $20 \%$ criterion (Fig. 7C). These results indicate that activation of PKC underlies spine plasticity evoked by glutamate although it did not affect dendritic width.

\section{Glutamate-induced changes in $\left[\mathrm{Ca}^{2+}\right] \mathrm{i}$ in young vs. mature cultures}

NMDAR activation, which is important for glutamate-induced plasticity, leads to influx of calcium into the post-synaptic cell. This elevation of $\left[\mathrm{Ca}^{2+}\right]$ i further induces calcium release from internal stores. Age-dependent differences in calcium handling, including calcium clearance and calcium-induced calcium release (CICR), may influence glutamate-induced plasticity. The following experiments were conducted to examine these possibilities.

Calcium imaging was used to monitor $\left[\mathrm{Ca}^{2+}\right] \mathrm{i}$ in young and mature cultures following a brief exposure to glutamate. The imaging experiments were conducted in the presence of $0.5 \mu \mathrm{m}$ TTX to block network activity and enable a better estimation of the $\left[\mathrm{Ca}^{2+}\right] \mathrm{i}$ clearance process. Both young and mature cells showed an immediate and fast rise in $\left[\mathrm{Ca}^{2+}\right]$ i following application of glutamate (35 cells, two coverslips and 32 cells, three coverslips, respectively) (Fig. 8A,B). Experiments conducted without TTX led to the same observations (data not shown). In young cells, the initial $\left[\mathrm{Ca}^{2+}\right] \mathrm{i}$ increase was followed by a rapid recovery back to baseline following washout of glutamate. In contrast, while the initial fast rise and the peak of $\left[\mathrm{Ca}^{2+}\right] \mathrm{i}$ in mature cells

\section{Learning \& Memory \\ www.learnmem.org}


A

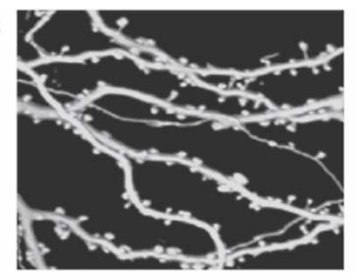

B

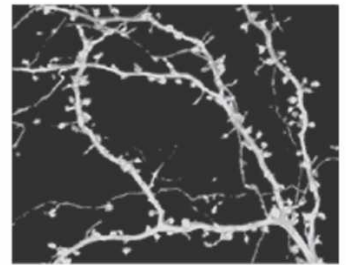

C

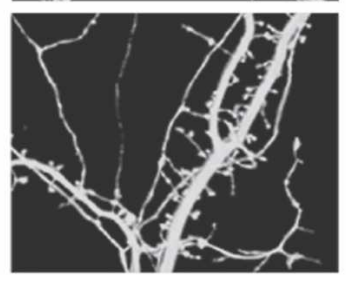

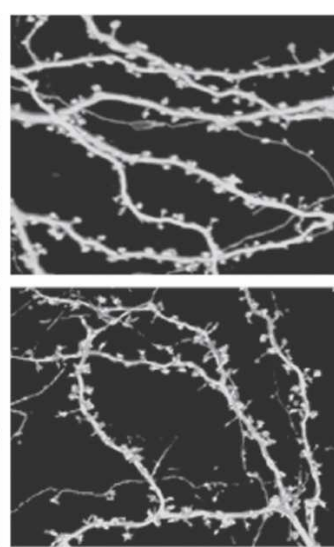

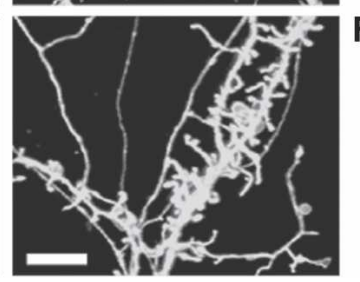

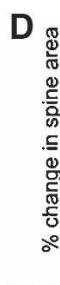

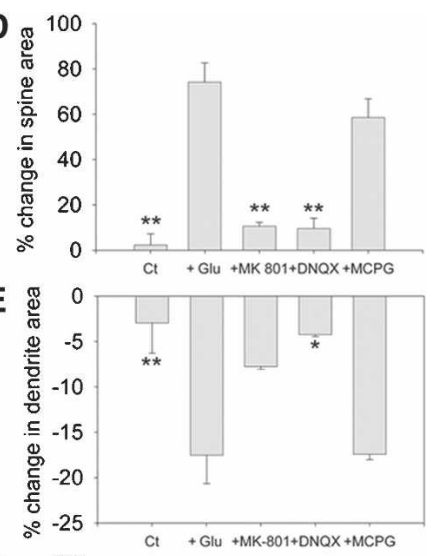

$\mathbf{F}$

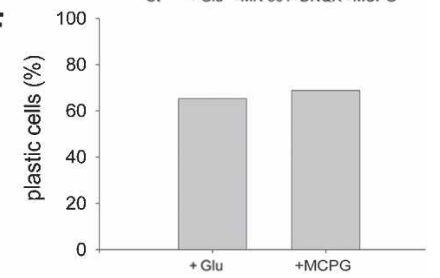

Figure 6. Blockade of NMDARs and AMPARs but not mGluRs prevents glutamate-induced spine swelling and dendritic shrinkage. $(A)$ Three-dimensional reconstructed images of spines and dendrites following blockade of NMDARs by MK-801 before (left) and $45 \mathrm{~min}$ after (right) glutamate application. (B) Same as in $A$, but blocking AMPARs with DNQX. (C) Same as in A, but blocking mGluRs with MCPG. Scale bar, $10 \mu \mathrm{m}$. (D) The average increase in spine area following glutamate application is significantly smaller in the presence of MK-801 (11.32\%; two coverslips, five cells, 100 spines) and DNQX (9.59\%; two coverslips, eight cells, 100 spines) but not MCPG (58.59\%; three coverslips, nine cells, 100 spines) compared with glutamate experiments (74.42\%; six coverslips, 13 cells, 167 spines). In the control cases, there was no change in spine area within 45 min of observation. ${ }^{* *} P<0.01$. (E) The average reduction in dendrite area following glutamate application is smaller in the presence of MK-801 (7.75\%; two coverslips, five cells, 25 segments) and DNQX (4.25\%; two coverslips, five cells, 25 segments) but not MCPG (17.45\%; three coverslips, 10 cells, 30 segments) compared with glutamate experiments (Glu; 17.8\%; three coverslips, 10 cells, 30 segments), ${ }^{*} P<0.05$, ${ }^{* \star} P<0.01$. ( $P$ ) The percentage of plastic cells in the presence of MCPG is similar to glutamate. $\chi_{(1)}^{2}=0.07$.

was similar to that of young cells, it was followed by a subsequent, slower additional rise in $\left[\mathrm{Ca}^{2+}\right] \mathrm{i}$. Only $4 \mathrm{~min}$ after the beginning of glutamate washout, $\left[\mathrm{Ca}^{2+}\right]$ i reached its peak. As opposed to young cells, $\left[\mathrm{Ca}^{2+}\right]$ i clearance was very slow in the mature ones. Fifteen minutes after washout, $\left[\mathrm{Ca}^{2+}\right] \mathrm{i}$ was still higher than baseline, and $48 \mathrm{~min}$ after the washout, [ $\left.\mathrm{Ca}^{2+}\right]$ i still did not reach baseline (Fig. 8D). These results are in sharp contrast to the lack of a prolonged effect of glutamate on resting membrane properties of the recorded neurons (see above). These results indicate that glutamate application induces an increase in $\left[\mathrm{Ca}^{2+}\right] \mathrm{i}$, which is transient in young cells and long-lasting in mature ones.

\section{Blockade of either AMPARs or NMDARs prevents the long-lasting effect of glutamate on $\left[\mathrm{Ca}^{2+}\right] \mathrm{i}$}

As it was shown that both AMPARs and NMDARs are necessary for the induction of plasticity, calcium imaging experiments were conducted in the presence of $20 \mu \mathrm{M}$ DNQX or $10 \mu \mathrm{M}$ MK801 to specifically block the respective receptors. Mature cells ( $n=13$ ) were exposed to $20 \mu \mathrm{M}$ DNQX for $2.5 \mathrm{~min}$ in order to examine the basal level of $\left[\mathrm{Ca}^{2+}\right] \mathrm{i}$. One-minute application of a solution containing $200 \mu \mathrm{M}$ glutamate and $20 \mu \mathrm{M}$ DNQX resulted in a fast increase in $\left[\mathrm{Ca}^{2+}\right]$ i. Following washout of glutamate, a fast decrease in $\left[\mathrm{Ca}^{2+}\right]$ i was observed. Ten minutes after the beginning of glutamate washout, $\left[\mathrm{Ca}^{2+}\right]$ i returned to baseline values (data not shown).

Application of $200 \mu \mathrm{M}$ glycine and $10 \mu \mathrm{M}$ MK-801 in a $\mathrm{Mg}^{2+}$-free medium for $5 \mathrm{~min}$ was used to activate and block synaptic NMDARs. No significant change in $\left[\mathrm{Ca}^{2+}\right] \mathrm{i}$ was observed during this period. Glutamate application resulted in an increase in $\left[\mathrm{Ca}^{2+}\right] \mathrm{i}$, and its washout resulted in fast $\left[\mathrm{Ca}^{2+}\right] \mathrm{i}$ clearance. $\left[\mathrm{Ca}^{2+}\right]$ i reached baseline levels 10 min after the beginning of washout (data not shown). These results indicate that both AMPAR and NMDAR activity are needed for glutamate induction of a long-lasting $\left[\mathrm{Ca}^{2+}\right]$ i elevation.

\section{Facilitation of $\left[\mathrm{Ca}^{2+}\right]$ i clearance in mature cultures changes their} response to glutamate application $\left[\mathrm{Ca}^{2+}\right]$ i was monitored in 50 mature cells (two coverslips) following a 1-min glutamate application and washout in a calcium-free medium. The facilitation of $\left[\mathrm{Ca}^{2+}\right]$ i clearance was found to change the response of the cells. Glutamate application induced a fast increase of $\left[\mathrm{Ca}^{2+}\right]$ i followed by an immediate decline following washout of glutamate, and 50 min later, the $\left[\mathrm{Ca}^{2+}\right] \mathrm{i}$ was already back to baseline (Fig. 8C,D). Morphological analysis was conducted under the same conditions for nine cells (one coverslip). Under these conditions, only one cell responded to glutamate by expressing morphological plasticity. All other eight cells did not show any change (data not shown). These experiments indicate that the efficiency of $\left[\mathrm{Ca}^{2+}\right]$ i clearance plays a crucial role in the induction of plasticity such that fast $\left[\mathrm{Ca}^{2+}\right]$ i clearance interferes with the ability of the cells to express morphological plasticity.

\section{Discussion}

Exposure to glutamate had been demonstrated 35 yr ago to cause neurodegeneration (Olney and Sharpe 1969). Under normal conditions, neuronal uptake systems remove synaptically released glutamate from the extracellular space before toxicity occurs (Schousboe 1981). However, in the wake of a hypoxic-ischemic event, these systems are malfunctioning, and the exposure to glutamate begins a chain of events leading to cell death. Exposure to only $100 \mu \mathrm{M}$ glutamate for 5 min destroys large numbers of cultured cortical neurons, which is partly mediated by a toxic influx of extracellular calcium (Choi et al. 1987; Choi and Rothman 1990). In vivo microdialysis experiments have shown that extracellular glutamate levels rise from under $5 \mu \mathrm{m}$ to $30 \mu \mathrm{m}$ within the first $10 \mathrm{~min}$ following ischemia, and to $500 \mu \mathrm{m}$ after half an hour (Benveniste et al. 1984; Hagberg et al. 1985; Choi et al. 1987). These and other studies point to the physiological relevance of studying the plastic events following glutamate exposure in hippocampal cultures.

Neuronal plasticity, including potentiation of EPSC amplitudes and mEPSC frequencies, as well as microstructural plasticity have been reported previously in 10-20 DIV hippocampal cultures after a brief glutamate application (Malgaroli and Tsien 1992; Antonova et al. 2001; Ninan and Arancio 2004; Wang et al. 2005). Here we report morphological plasticity and potentiation of physiological responses (EPSCs and mEPSCs) only in cultures 

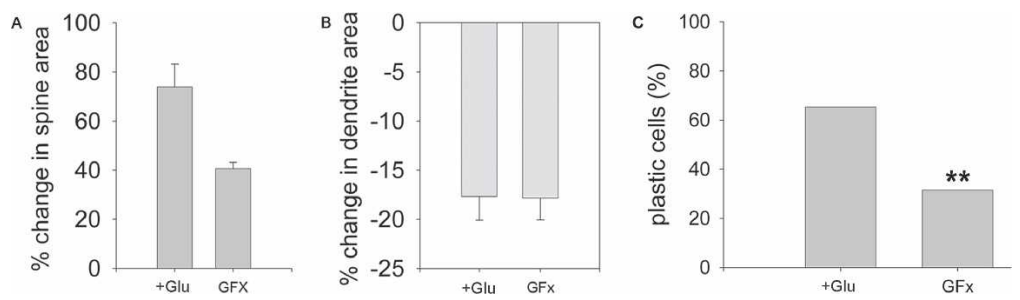

Figure 7. Blockade of PKC significantly reduces morphological plasticity. $(A)$ The average increase in spine area is lower than glutamate experiments (Glu) in the presence of GF109203X (GFX; 41.09\%). $P=0.08$. (B). The average reduction in dendritic width in the presence of GF109203X is similar to glutamate experiments (17.97\%). (C) The percentage of plastic cells is smaller in the presence of GF109203X compared with glutamate. $\chi_{(1)}^{2}=6.68,{ }^{* *} P<0.01$.

$>18$ DIV, while younger cultures (10-18 DIV) showed depression of EPSCs. This discrepancy between our and previous studies, i.e., depression versus potentiation of EPSCs in young cultures, is surprising, and may be explained by different experimental procedures, which may affect the maturation of the cultures (e.g., different rat and mice strains, dissociated cultures plated on a monolayer of glia vs. glass, different growth media, usage of kynurenic acid, different $\mathrm{Mg}^{2+}$ concentrations in the recording medium, age of dissection, etc.). In our hands, however, the morphological and physiological plasticities are clearly and reproducibly age dependent.

A brief application of glutamate induced LTP in mature dissociated cultures of rat hippocampus. The electrophysiological changes, including an increase in evoked synaptic responses as well as an increase in both frequency and amplitudes of mEPSCs, indicate that glutamate is likely to produce changes in presynaptic release properties as well as post-synaptic glutamate receptors. These changes were accompanied by striking morphological alterations in spines and dendrites. Since the morphological changes occur gradually, starting from $5 \mathrm{~min}$ after exposure to glutamate and developing for at least $45 \mathrm{~min}$, it seems that they are not responsible for the initiation of the electrophysiological LTP. In fact, even their importance for its maintenance needs to be demonstrated. It has been shown previously that larger spines are more stable than are small ones and tend to exhibit higher AMPAR levels (Takumi et al. 1999). The higher concentration of AMPARs enables an enhanced response to glutamate release. These findings led to the proposition that large spines play a role in the persistence of "memories" for a long time, whereas small, unstable spines serve as "learning spines" (Kasai et al. 2003). Consistent with this hypothesis, we found that the initial spine size affects its reactivity to glutamate. Whereas large spines exhibit a moderate increase in size following exposure to glutamate, small ones increased by an average of more than twofold.

Following exposure to glutamate, spines and dendrites expressed an opposite behavior: Spines increased in size, whereas dendrite diameter shrunk. This behavior indicates that the morphological alternations represent a genuine form of plasticity and are not a consequence of an overall increase in fluorescence following enhanced synthesis of new GFP molecules. Shrinkage of the dendrite can probably facilitate spine swelling by supplying it with membrane and cytoplasm. Along with changes in spines' and dendrites' dimensions, glutamate induced spinogenesis and marked transformation of the shape of existing spines. This phenomenon was observed before, using different chemical and electrical stimulation protocols (Engert and Bonhoeffer 1999; Goldin et al. 2001).

Glutamate can depolarize the post-synaptic neurons by acting at both synaptic and extra-synaptic receptors. While we did not estimate the proportion of synaptic/nonsynaptic receptors, we believe that the effects seen here must involve activation of tating the activation of NMDAR. However, usage of $\mathrm{Mg}^{2+}$-free medium did not overcome the blockade of plasticity by the AMPA antagonist DNQX, indicating that AMPARs play an independent role in induction of plasticity. In support of this assertion, blockade of either NMDARs or AMPARs eliminated the long-lasting increase in $\left[\mathrm{Ca}^{2+}\right] \mathrm{i}$ along with the morphological change. This contrasts the common assumption that NMDARs, but not AMPARs, are involved in the initiation of LTP whereas the latter is mediating the maintenance of LTP (Bliss and Collingridge 1993). It is possible that at this particular developmental stage, the two glutamate receptor types are involved in the initiation of synaptic plasticity, unlike the case in the more adult or younger cells. Developmental differences in mechanisms of LTP have been alluded to before (see Isomura and Kato 1999).

One mechanism that could underlie the age-dependent plasticity involves the ability to raise the intracellular calcium concentration long enough to activate calcium-dependent processes. One major cause for somatic calcium changes are action potentials that depolarize the cell, allowing calcium influx via voltage gated calcium channels. However, the calcium and morphological changes that were observed herein did not require action potential discharges. Differences in calcium clearance properties between the mature and the young cells can be caused by differences in the amount of calcium that is released by internal calcium stores, or by dissimilar abilities of mature vs. young cells to pump out calcium. Our results indicate that while in the young cells, calcium elevation was transient, returning to baseline soon after washout of glutamate, in the mature cells the level of $\left[\mathrm{Ca}^{2+}\right] \mathrm{i}$ remained in a plateau level for many minutes, long after membrane potential recovered, and this was associated with the morphological change. Expanding the duration of elevated $\left[\mathrm{Ca}^{2+}\right] \mathrm{i}$ in the young cells mimicked the morphological changes typical of the adult cells (data not shown), while speeding up the recovery in the adults blocked the morphological change. Calcium stores have been associated with LTP and morphological plasticity (Harvey and Collingridge 1992), and indeed, in preliminary experiments we found that blockade of release of calcium from stores, using $1 \mu \mathrm{M}$ thapsigargin, also reduced the sustained calcium responses to glutamate in the mature cultures (data not shown), indicating that calcium stores are relatively slow to mature in these cultured neurons and that they may eventually contribute to the observed rise of $\left[\mathrm{Ca}^{2+}\right] \mathrm{i}$.

These results suggest that an age-dependent difference in calcium handling is responsible for differences in the induction of morphological plasticity. The change in calcium handling was probably not due to an influx mechanism but rather to ability to release calcium from stores, which would perpetuate the high level of $\left[\mathrm{Ca}^{2+}\right] \mathrm{i}$ in the affected cells.

This also implies that the duration of $\left[\mathrm{Ca}^{2+}\right] \mathrm{i}$ elevation is crucial for induction of plasticity. There are additional experiments that support this hypothesis; application of glutamate for $5 \mathrm{~min}$ in young cultures induces a long-lasting elevation in 
A
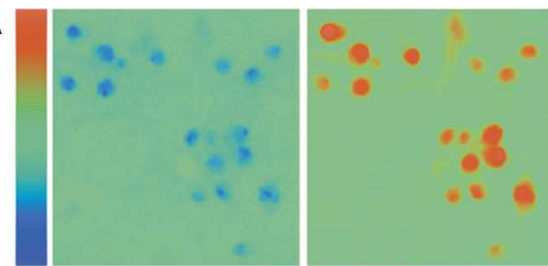

B
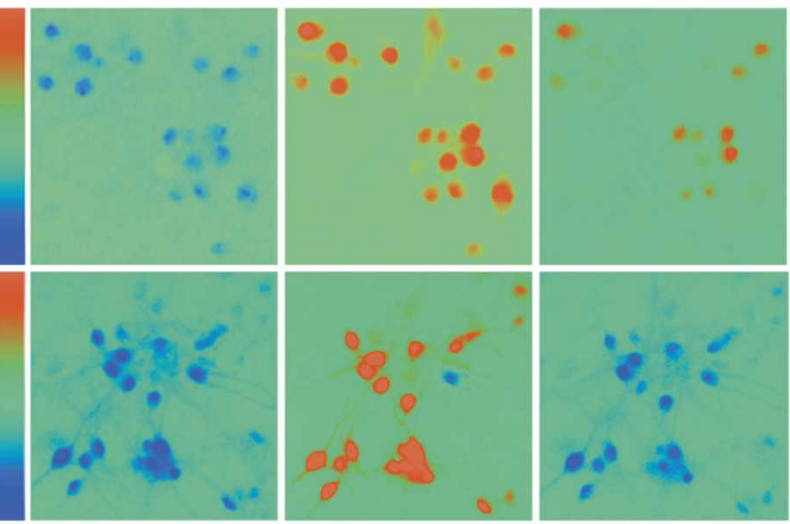

C
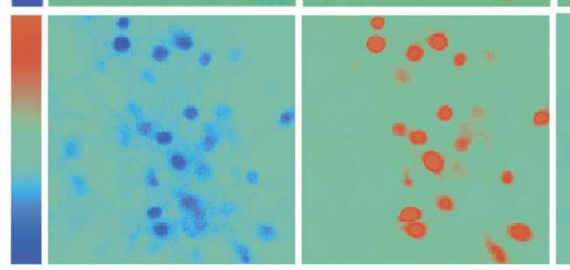

D
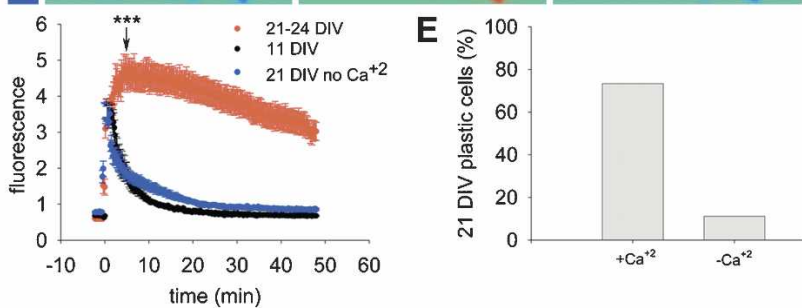

Figure 8. Glutamate induces a long-lasting increase in $\left[\mathrm{Ca}^{2+}\right] \mathrm{i}$ in mature cells, but only a transient increase in young cells. Facilitation of $\left[\mathrm{Ca}^{2+}\right] \mathrm{i}$ clearance in mature cultures abolishes glutamate-induced longlasting elevation of $\left[\mathrm{Ca}^{2+}\right] \mathrm{i}$ and reduces morphological plasticity. ( $A$ ) Calcium imaging of mature cells before (left), during (middle), and $48 \mathrm{~min}$ after (right) exposure to glutamate. Color bar illustrates tentative calcium concentration scales, $0.45-15$. (B) Same as in $A$, but with young cells. Scale bar, 0.4-15.2. (C) Same as in $A$, but glutamate was washed out with calcium free medium. Scale bar, 0.4-15.2. (D) Average fluorescence levels in mature and young cells following exposure to glutamate at time 0 , and washout with a calcium-containing or calcium-deficient medium. $\left[\mathrm{Ca}^{2+}\right] \mathrm{i}$ levels in young vs. mature cells were compared by $t$-test $5 \mathrm{~min}$ following glutamate application. ${ }^{* *} P<0.001$. $\left[\mathrm{Ca}^{2+}\right] \mathrm{i}$ levels in young vs. mature cells that were washed in calcium-deficient medium were compared by $t$-test 5 min following glutamate application. $P<0.05$. (E) The proportion of modified neurons is markedly reduced by washing them in calcium-deficient medium. In control, mature neurons exposed for $1 \mathrm{~min}$ to glutamate, most neurons change their morphology, whereas only one cell of eight studied changed its morphology in response to glutamate when washed with calcium-deficient medium. $\chi_{(1)}^{2}=8.71, P<0.003$.

$\left[\mathrm{Ca}^{2+}\right] \mathrm{i}$, as well as a morphological change akin to that produced in the mature cells (data not shown). Facilitation of calcium clearance in mature cultures by exposing the cells to a low calcium containing medium eliminated the long-lasting $\left[\mathrm{Ca}^{2+}\right] \mathrm{i}$ elevation and abolished, in most of the cases examined, morphological plasticity.

As indicated, the age of cells has a crucial effect on their plastic properties. Electrophysiologically, young cells showed an opposite behavior in response to glutamate application compared with mature ones; whereas mature cells produced LTP, young cells produced a large LTD following 1-min exposure to glutamate. These results correspond only partially with the morphological results that show spinogenesis and spine swelling in mature cultures but no significant change in young cultures. The remarkable LTD seen in the young cells did not have an obvious morphological correlate. This is in contrast to some recent sug- gestions that LTD is associated with shrinkage of spines (Zhou et al. 2004), but is consistent with other suggestions that LTD is associated with removal of AMPA receptors from synapses, but not necessarily with a morphological change (Xiao et al. 2001). One possible explanation for the striking LTD in the young cultures is related to the proposition that both LTP and LTD involve a rise of intracellular calcium concentration, with the latter being associated with a smaller rise than the former (Yang et al. 1999). It is thus possible that the added release of calcium from stores, found in the mature neurons can shift the calcium level into the range needed to produce LTP in the affected neurons. The relevance of an age-dependent raised level of $\left[\mathrm{Ca}^{2+}\right]$ i for the induction of LTP has been demonstrated before (Isomura and Kato 1999).

Regardless of the exact mechanism, the present results indicate that chemical stimulation that causes an increase in synaptic connectivity is associated with a slow increase in spine size. While there might be differences in the rate of increase of spine size between electrical and chemical stimulation, as implied from other studies (see above), the marked and sustained change in spine volume may underlie at least some types of functional synaptic plasticity. Other types, more typical of the younger cells, may be expressed not by a change in spine size but rather by growth of novel spines, or by presynaptic mechanisms (Goldin et al. 2001; Ivenshitz and Segal 2006).

\section{Materials and Methods}

\section{Culture preparation}

Cultures were prepared as detailed elsewhere (Goldin et al. 2001). Briefly, rat pups were decapitated on day of birth (P0), their brains removed, and their hippocampi dissected in a chilled $\left(4^{\circ} \mathrm{C}\right)$, oxygenated Leibovitz L15 medium (Biological Industries). Cells were plated on Poly-L-Lysine-coated, round (13-mm) coverslips, onto a monolayer of glia grown on the glass for 1-2 wk prior to the plating. About $0.4-0.5 \times 10^{6}$ cells in $1 \mathrm{~mL}$ of medium were plated in each well of a 24 -well plate. Cells were left to grow in the incubator at $37^{\circ} \mathrm{C}, 5 \% \mathrm{CO}_{2}$ for $4 \mathrm{~d}$, at which point the medium was changed to $10 \%$ HS in enriched MEM, plus a mixture of 5'-fluoro-2-deoxyuridine/uridine (Sigma; $20 \mu \mathrm{g}$ and 50 $\mu \mathrm{g} / \mathrm{mL}$, respectively), to block glial proliferation. Four days later the medium was changed to $10 \%$ HS in MEM, and no further changes were made.

\section{Transfection}

A lipofectamine $2000 \mathrm{mix}$ was prepared at $1.2 \mu \mathrm{L}$ with $50 \mu \mathrm{L}$ optimem per well, and incubated for $5 \mathrm{~min}$ at room temperature. This was mixed with $1.2 \mu \mathrm{g}$ per well total GFP plasmid in $50 \mu \mathrm{L}$ optimem and incubated for $15 \mathrm{~min}$ at room temperature. The mix was then added to the cultures for $4 \mathrm{~h}$ until the medium was changed. Transfection was carried out on seven DIV cultures.

\section{Experimental setup}

Cultures were washed with a standard recording medium and placed in a recording chamber. Recording medium contained (in $\mathrm{mM}$ ): $\mathrm{NaCl}, 129 ; \mathrm{KCl}, 4 ; \mathrm{MgCl}_{2}, 1 ; \mathrm{CaCl}_{2}, 2$; glucose, 10; HEPES 10; pH was adjusted to 7.4 with $\mathrm{NaOH}$; and osmolarity to 320 mOsm with sucrose. The chamber was placed on the stage of an inverted Zeiss confocal laser-scanning microscope (LSM-510). High-resolution thin optical sections from three to five cells were obtained from each cover glass before and at several time points after a 1-min exposure to $200 \mu \mathrm{M}$ glutamate, which was followed by wash with the standard recording medium. The medium was replaced every $15 \mathrm{~min}$ to prevent changes in osmolarity due to evaporation. Pharmacological agents were added both to the standard recording solution and to the glutamate solution, unless indicated otherwise. 


\section{Morphological analysis}

Analysis of the spine cross-section area and dendrite width was conducted off line using the Zeiss LSM image browser. Changes in the spine area were measured as follows: First, random spines were chosen where the optical slice in which the largest crosssection area of the spine was in focus. Then, the area of the spine was measured using the overlay function of the software. This function enables a precise drawing of a spine's contour. The same procedure was carried out for the same spine in the images taken after the glutamate application. Eventually the two area values were compared. Changes in dendrite width were measured in a similar way. After the optical slice in which the dendrite was in focus was chosen, the area of a $25-\mu m$-length segment was measured. The same measurement was conducted for the same segment in the images taken following glutamate application. Finally, the difference between the values was calculated. As the length of the dendritic segment $(25 \mu \mathrm{m})$ was kept constant throughout the analysis procedure, the values actually represent changes in dendrite width. To validate the reliability of the results, the area of 30 spines was measured independently by two different observers. The measurements were carried out both before and $45 \mathrm{~min}$ after glutamate application. The correlation (r) between the two observers was found to be 0.98 and 0.99 for the measurements before and 45 min after glutamate application.

Specific care was taken to avoid biased selection and interpretation of the results. Consequently, medium spiny, pyramidal-like neurons, but no aspiny or excessively spiny cells were selected for image acquisition. In all cases, the dendrite/spine segments were chosen only according to the unbiased image taken before the glutamate application. The single criterion used for the selection of spines or dendrites for the analysis was the appearance in focus of the whole spine element in a single optical slice. All the pictures appear as a three-dimensional reconstruction for the convenience of the reader. The reconstruction was carried out using the transparent projection track of the imaging software.

Following glutamate application, usually only a subpopulation of cells exhibited changes in spine and dendrite morphology, as well as spinogenesis. A minimum of $20 \%$ increase in spine area was set as a criterion to classify cells as "plastic," and only these cells were taken for quantitative analysis. Pharmacological agents were said to have a blocking effect on the increase in spine cross-section area if none of the cells on the slide showed any morphological plasticity. In cases where none of the cells reached the $20 \%$ criterion, all cells were taken for quantitative analysis.

\section{Calcium imaging}

Cultures were incubated for $1 \mathrm{~h}$ at room temperature with the standard recording medium containing $2 \mu \mathrm{M}$ Fura-2AM. Cells were imaged thereafter on the stage of an inverted Olympus microscope, equipped with a Till Photonics light source and an Andor iXon CCD camera. Fluorescence levels to illumination at $340 / 380 \mathrm{~nm}$ were recorded. The results are presented as the ratio of fluorescence at $340 / 380 \mathrm{~nm}$ rather than the calculated calcium concentrations.

\section{Electrophysiology}

Cultures at 11-18 (young) or 19-25 (mature) DIV were transferred to a recording chamber placed on the stage of a Zeiss Axioscope upright microscope and washed in a standard recording medium. Hippocampal neurons were recorded with patch pipettes containing (in $\mathrm{mM}$ ): K-gluconate, 136; $\mathrm{KCl}, 10$; $\mathrm{NaCl}, 5$; HEPES, 10; EGTA, 0.1; Na-GTP, 0.3; Mg-ATP, 1; phosphocreatine, $5 ; \mathrm{pH} 7.2$ with a resistance in the range of 5-10 M $\Omega$. Criteria for accepting a recording included membrane potential of at least $-55 \mathrm{mV}$, and series resistance and capacitance of $<40 \mathrm{M} \Omega$ and 40 $\mathrm{pF}$, respectively, that were not changed significantly throughout the recording session. Signals were amplified with Axopatch 200A and Axoclamp-2 amplifiers and recorded with pClamp8 (Axon Instruments). To study synaptic connections, dual wholecell recordings were conducted. Minimal DC current required to evoke an action potential was injected into the presynaptic neu- ron in current clamp mode, and an average of three post-synaptic responses was recorded in voltage clamp mode at 10-sec intervals every 30 sec over half an hour. When recording mEPSCs, $0.5 \mu \mathrm{M}$ TTX was added to the medium, and neurons were clamped at $-60 \mathrm{mV}$. Measurements of mEPSC amplitude and frequency commenced $\sim 10 \mathrm{~min}$ after complete washout of the glutamate application and once the membrane of the recorded neurons stabilized back at resting potential. The data were summarized and analyzed off-line using Clampfit8, SigmaPlot and Origin, followed by $t$-tests. mEPSC recordings were analyzed off-line using MiniAnalysis software with an amplitude detection threshold of 9pA (Synaptosoft).

\section{Statistical analysis}

The statistical significance of the results was verified by $t$-tests, $\chi^{2}$ tests, linear regression, and ANOVA, as the case requires, using SigmaPlot and SPSS programs. To set the $N$ for the statistical analysis, a three-way ANOVA was carried out for the data concerning the influence of glutamate application on changes in spine area. The statistical analysis was carried out with "change in spine area" as a dependent variable, "coverslip" as an independent variable, and "cell" and "spine" as random factors (nested). The analysis showed no significant main effects for "coverslip" $\left(F_{(3,5)}<1\right)$, "cell" $\left(F_{(3,3)}<1\right)$, and "spine" $\left(F_{(33,18)}=1.202, P>0.346\right)$. Regarding the interactions, "coverslip" × "spine" was $F_{(57,36)}<1$, "cell" $\times$ "spine" was $F_{(27,36)}<1$, and "coverslip" $\times$ "cell" was $F_{(4,36)}=3.468(P<0.017)$. In exploring the significant interaction "coverslip" $\times$ "cell" by two-way ANOVA, we found the "coverslip" factor to be significant: $F_{(5,154)}=2.776(P<0.02)$. Accordingly, $N$ was set to be the number of coverslips.

\section{Acknowledgments}

We thank V. Greenberger for preparation of the cultures, Dr. E. Korkotian for help with the morphological reconstruction, and Dr. A. Avital for help with statistical analysis. This research is supported by a grant from the Israel Science Foundation (grant no. $381 / 02$ )

\section{References}

Antonova, I., Arancio, O., Trillat, A.C., Wang, H.G., Zablow, L., Udo, H., Kandel, E.R., and Hawkins, R.D. 2001. Rapid increase in clusters of presynaptic proteins at onset of long-lasting potentiation. Science 294: $1547-1550$.

Bagal, A.A., Kao, J.P., Tang, C.M., and Thompson, S.M. 2005. Long-term potentiation of exogenous glutamate responses at single dendritic spines. Proc. Natl. Acad. Sci. 102: 14434-14439.

Benveniste, H., Drejer, J., Schousboe, A., and Diemer, N.H. 1984. Elevation of the extracellular concentrations of glutamate and aspartate in rat hippocampus during transient cerebral ischemia monitored by intracerebral microdialysis. J. Neurochem. 43: $1369-1374$.

Bliss, T.V. and Collingridge, G.L. 1993. A synaptic model of memory: Long-term potentiation in the hippocampus. Nature 361: 31-39.

Carroll, R.C., Lissin, D.V., von Zastrow, M., Nicoll, R.A., and Malenka, R.C. 1999. Rapid redistribution of glutamate receptors contributes to long-term depression in hippocampal cultures. Nat. Neurosci. 2: $454-460$

Choi, D.W. and Rothman, S.M. 1990. The role of glutamate neurotoxicity in hypoxic-ischemic neuronal death. Annu. Rev. Neurosci. 13: 171-182.

Choi, D.W., Maulucci-Gedde, M., and Kriegstein, A.R. 1987. Glutamate neurotoxicity in cortical cell culture. J. Neurosci. 7: 357-368.

Engert, F. and Bonhoeffer, T. 1999. Dendritic spine changes associated with hippocampal long-term synaptic plasticity. Nature 399: 19-21.

Goldin, M., Segal, M., and Avignone, E. 2001. Functional plasticity triggers formation and pruning of dendritic spines in cultured hippocampal networks. J. Neurosci. 21: 186-193.

Hagberg, H., Lehmann, A., Sandberg, M., Nystrom, B., Jacobson, I., and Hamberger, A. 1985. Ischemia-induced shift of inhibitory and excitatory amino acids from intra- to extracellular compartments. $J$. Cereb. Blood Flow Metab. 5: 413-419.

Halpain, S., Hipolito, A., and Saffer, L. 1998. Regulation of F-actin stability in dendritic spines by glutamate receptors and calcineurin. J. Neurosci. 18: 9835-9844.

Harvey, J. and Collingridge, G.L. 1992. Thapsigargin blocks the 
induction of long-term potentiation in rat hippocampal slices. Neurosci. Lett. 139: 197-200.

Isomura, Y. and Kato, N. 1999. Action potential-induced dendritic calcium dynamics correlated with synaptic plasticity in developing hippocampal pyramidal cells. J. Neurophysiol. 82: 1993-1999.

Ivenshitz, M. and Segal, M. 2006. Simultaneous NMDA-dependent long-term potentiation of EPSCs and long-term depression of IPSCs in cultured rat hippocampal neurons. J. Neurosci. 26: 1199-1210.

Kasai, H., Matsuzaki, M., Noguchi, J., Yasumatsu, N., and Nakahara, H. 2003. Structure-stability-function relationships of dendritic spines. Trends Neurosci. 26: 360-368.

Lang, C., Barco, A., Zablow, L., Kandel, E.R., Siegelbaum, S.A., and Zakharenko, S.S. 2004. Transient expansion of synaptically connected dendritic spines upon induction of hippocampal long-term potentiation. Proc. Natl. Acad. Sci. 101: 16665-16670.

Maletic-Savatic, M., Malinow, R., and Svoboda, K. 1999. Rapid dendritic morphogenesis in CA1 hippocampal dendrites induced by synaptic activity. Science 283: 1923-1927.

Malgaroli, A. and Tsien, R.W. 1992. Glutamate-induced long-term potentiation of the frequency of miniature synaptic currents in cultured hippocampal neurons. Nature 357: 134-139.

Matsuzaki, M., Honkura, N., Ellis-Davies, G.C., and Kasai, H. 2004. Structural basis of long-term potentiation in single dendritic spines. Nature 429: 761-766.

Nikonenko, I., Jourdain, P., and Muller, D. 2003. Presynaptic remodeling contributes to activity-dependent synaptogenesis. $J$. Neurosci. 23: 8498-8505.

Ninan, I. and Arancio, O. 2004. Presynaptic CaMKII is necessary for synaptic plasticity in cultured hippocampal neurons. Neuron 42: $129-141$.

Olney, J.W. and Sharpe, L.G. 1969. Brain lesions in an infant rhesus monkey treated with monsodium glutamate. Science 166: 386-388.

Otmakhov, N., Tao-Cheng, J.H., Carpenter, S., Asrican, B., Dosemeci, A.,
Reese, T.S., and Lisman, J. 2004. Persistent accumulation of calcium/calmodulin-dependent protein kinase II in dendritic spines after induction of NMDA receptor-dependent chemical long-term potentiation. J. Neurosci. 24: 9324-9331.

Parnavelas, J.G., Globus, A., and Kaups, P. 1973. Continuous illumination from birth affects spine density of neurons in the visual cortex of the rat. Exp. Neurol. 40: 742-747.

Schousboe, A. 1981. Transport and metabolism of glutamate and GABA in neurons and glial cells. Int. Rev. Neurobiol. 22: 1-45.

Takumi, Y., Ramirez-Leon, V., Laake, P., Rinvik, E., and Ottersen, O.P. 1999. Different modes of expression of AMPA and NMDA receptors in hippocampal synapses. Nat. Neurosci. 2: 618-624.

Trommald, M., Hulleberg, G., and Andersen, P. 1996. Long-term potentiation is associated with new excitatory spine synapses on rat dentate granule cells. Learn. Mem. 3: 218-228.

Wang, H.G., Lu, F.M., Jin, I., Udo, H., Kandel, E.R., de Vente, J., Walter, U., Lohmann, S.M., Hawkins, R.D., and Antonova, I. 2005. Presynaptic and postsynaptic roles of NO, cGK, and RhoA in long-lasting potentiation and aggregation of synaptic proteins. Neuron 45: 389-403.

Xiao, M.Y., Zhou, Q., and Nicoll, R.A. 2001. Metabotropic glutamate receptor activation causes a rapid redistribution of AMPA receptors. Neuropharmacology 41: 664-671.

Yang, S.N., Tang, Y.G., and Zucker, R.S. 1999. Selective induction of LTP and LTD by postsynaptic $\left[\mathrm{Ca}^{2+}\right]_{\mathrm{i}}$ elevation. J. Neurophysiol. 81: 781-787.

Zhou, Q., Homma, K.J., and Poo, M.M. 2004. Shrinkage of dendritic spines associated with long-term depression of hippocampal synapses. Neuron 44: 749-757.

Received June 18, 2006; accepted in revised form July 21, 2006. 


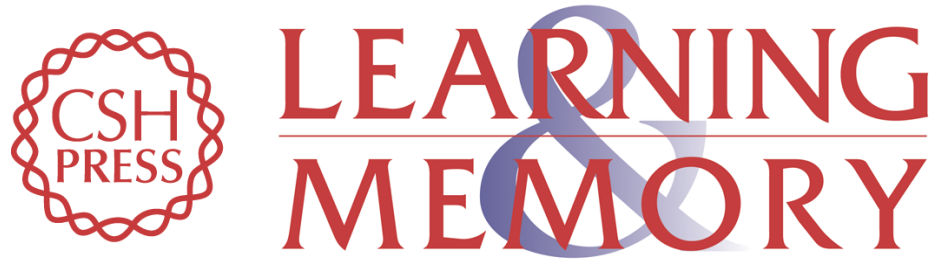

\section{Age-dependent glutamate induction of synaptic plasticity in cultured hippocampal neurons}

Stav Sapoznik, Miriam Ivenshitz and Menahem Segal

Learn. Mem. 2006, 13: originally published online November 13, 2006

Access the most recent version at doi:10.1101/lm.351706

References This article cites 31 articles, 12 of which can be accessed free at:

http://learnmem.cshlp.org/content/13/6/719.full.html\#ref-list-1

License

Email Alerting Receive free email alerts when new articles cite this article - sign up in the box at the Service top right corner of the article or click here. 